\title{
Pan-AKT Inhibitor ARQ751
}

National Cancer Institute

\section{Source}

National Cancer Institute. Pan-AKT Inhibitor ARQ751. NCI Thesaurus. Code C128250.

An orally bioavailable pan inhibitor of the serine/threonine protein kinase AKT (protein kinase B) enzyme family with potential antineoplastic activity. Upon oral administration, AKT inhibitor ARQ 751 selectively binds to and inhibits the activity of the AKT isoforms 1, 2 and 3, which may result in the inhibition of the phosphatidylinositol 3-kinase (PI3K)/AKT signaling pathway. This may lead to a reduction in tumor cell proliferation and the induction of tumor cell apoptosis. The AKT signaling pathway is often deregulated in cancer and is associated with tumor cell proliferation, survival and migration. 